\title{
Delay Efficient Vedic Multiplier for DSP
}

\author{
Nidhi Gaur, Anu Mehra, Shikha Bathla, Pradeep Kumar
}

\begin{abstract}
Multipliers are very essential blocks in any arithmetic and logic unit, accumulators and Digital signal processors. Due to the enlarging check on delay, design of faster multipliers is desired. Amidst numerous multipliers, Vedic multipliers are favored for their speed of operation. There are sixteen sutras in Vedic mathematics out of which four are multiplication techniques. "URDHVA TIRYAKBHYAM" is the most efficient vedic multiplication technique in terms of speed. In this paper we aim to develop a multiplier using Ripple Carry Adder and parallel prefix adders which carry out the "URDHVA TIRYAKBHYAM" sutra with improved speed of operation by providing the minimum delay for the multiplication of numbers regardless of their bit sizes. $A$ vast majority of the engineering domain consists of ubiquitous technologies like DSP. As it is one of the most rapid growing technologies of the 21st Century, it faces challenges and improvisation at each step. Engineers are working diligently to improve the quality of Digital Signal processors and major breakthroughs are being made at a very good rate. Proposed multiplier could be applied for such DSP applications. Verilog language has been used for the coding. Xilinx Vivado Tool is used for synthesis and Model Sim 5.4 has been used for simulation.
\end{abstract}

Index Terms: Urdhva Tiryakbhyam, Vedic Multiplier, Ripple Carry Adder, Parallel Prefix Adder.

\section{INTRODUCTION}

India has been a land of discoveries in the field of mathematics from the very ancient times, be it the conception of 'zero' or the very famous Vedic mathematical Sutras. We have a rich ancient heritage. The ancient Indian texts named as 'Vedas' which is interpreted as knowledge, provide the key to Vedic Mathematics and in the year 1911 to 1918 Sri Bharati KrishnaTithaji rediscovered Vedic Sutras from these texts [1]. According to his study, Vedic Mathematics works on or is based on sixteen formulae or 'sutras'. "Urdhva-Tiryagbhyam" is one of the sixteen sutras and is translated as vertically and crosswise. It is one of the most used and generalized sutra because human mind also calculates in the same way as described by this sutra: vertically and crosswise. In this paper, Vedic multiplier has been proposed using "Urdhva- Tiryagbhyam" sutra which helps in achieving faster bit multiplication rates and renders the multiplier more delay efficient.

In the present times high speed multipliers [2] can be designed using various approaches. Array multiplier, Booth multiplier, Tree multiplier are few of the many examples of high speed multipliers. Speed of the multiplier

Revised Manuscript Submitted on June 15, 2019.

Nidhi Gaur, Department of ECE, Amity University, Uttar Pradesh, India. Anu Mehra, Department of ECE, Amity University, Uttar Pradesh, India. Shikha Bathla, Department of ECE, Amity University, Uttar Pradesh, India. Pradeep Kumar, Department of ECE, Amity University, Uttar Pradesh, India. can be bettered using reversible logic too [3]. The more speed efficient a multiplier is; the more operations can be implemented on it. A number of DCT [4], DSP and data path operations are feasible through the use of Vedic multipliers. Implementation of Vedic multipliers in the digital signal processing domain could be quite booming. Technologies such as image compression, video recording, speech recognition all involve the use of convolution, filtering and fast Fourier transform which comes under the field of DSP. Since multiplication is the fundamental step in the execution of these operations, the use of a high speed multiplier will surely improve the efficacy of the operation.

Many formulas and algorithms have been derived keeping a check on fast multiplication in mind such as Baugh-Wooley Algorithm, Modified Booth Algorithm and recording bits algorithm. Albeit these algorithms are fast and efficient but poor time efficiency is one of their drawbacks. To optimize the standard arithmetic operations, Vedic mathematics came into use and Vedic multipliers can be relied upon to increase the computational speed of the processor. When number of bits increase in an operation, a similar rise is observed in the delay and area of a multiplier. Thus proposed multiplier is studied for 2 bit, 4 bit, 8 bit, and 16 bit respectively.

\section{PROPOSED VEDIC MULTIPLIER}

In this paper, Vedic multiplier architecture is realized through structural modelling. First a basic $2 X 2$ vedic multiplier is designed. This multiplier is used as component for the design of higher bit multipliers along with the ripple carry adders and parallel prefix adders as components.

\section{A. $2 \times 2$ Vedic Multiplier}

A 2 bit Vedic multiplier is designed with direct use of "Urdhva- Tiryagbhyam" sutra for the arithmetic operation of two binary numbers. Two binary numbers of two bits each, for example $\mathrm{P}$ and $\mathrm{Q}$ are taken. A comprise of $\mathrm{P} 1 \mathrm{P} 0$ and $\mathrm{Q}$ is comprise of Q1Q0. Vertical multiplication of P0 (LSB) and Q0 (LSB) takes place first. The resultant product is kept as the LSB of the final result. Use of AND gate comes forward for the multiplication of $\mathrm{P} 0$ and $\mathrm{Q} 0$. The following step is to cross multiply LSB of number P that is P0 with the MSB of number Q that is Q1 and add them with the product generated as a result of cross multiplication of MSB of number P that is P1 with the LSB of number Q that is Q0. The circuitry required here is two AND gates and one Half Adder. This results in an output of two bits. LSB of the resultant output is employed as second bit of the final product and MSB is used as pre carry for the succeeding step. The 


\section{Delay Efficient Vedic Multiplier for DSP}

concluding step is the vertical multiplication of the MSB's of the two numbers that is $\mathrm{P} 1$ and Q1. The pre carry of the preceding step is added with the resultant product. Thus, the need of a new half adder again arises. The third and the fourth bit of the final result is the two bit output generated by the half adder. The final result is D2T2T1T0. Such is the 2X2 Vedic multiplication (Figure 1) process. Resulting equations are shown.

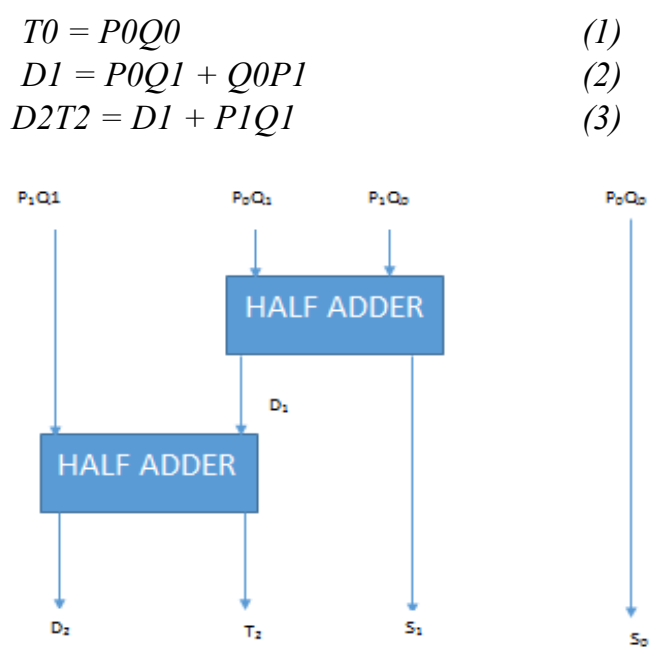

Fig 1. 2X2 Vedic Multiplier Architecture

\section{B. $4 X 4$ Vedic multiplier}

Delay efficient $4 \mathrm{X} 4$ Vedic multiplier (Figure 2) is realized using the modules of the 4 bit Brent Kung adder and the module of the 2X2 Vedic multiplier realized initially. Since Brent Kung adders are area efficient, so they are used here to make the design area efficient along with delay efficiency.

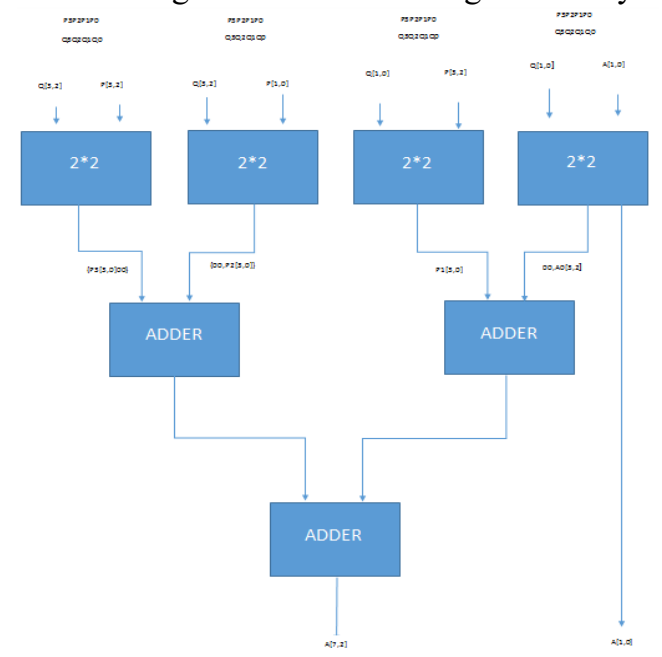

Fig 2. 4X4 Vedic Multiplier Architecture

\section{8X8 Vedic Multiplier}

Using the same modelling structure, Delay efficient $8 X 8$ Vedic Multiplier (Figure 3) is realized using the modules of 8 bit ripple Carry Adder and $4 \mathrm{X} 4$ Vedic Multiplier.

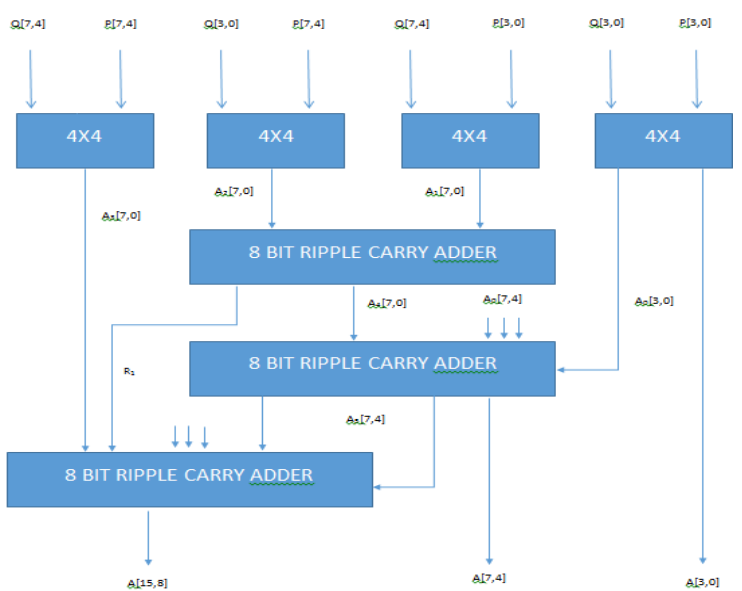

Fig 3. 8X8 Vedic Multiplier Architecture

\section{16X16 Vedic Multiplier}

Through the use of structural modelling, delay efficient 16X16 Vedic Multiplier (Figure 4) is realized using the modules of sixteen bit adder and the modules of $8 \mathrm{X} 8$ Vedic multiplier.

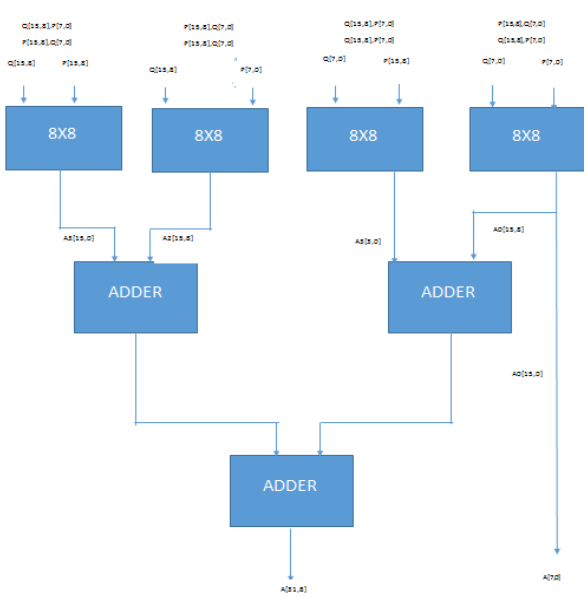

Fig 4. 16X16 Vedic multiplier Architecture

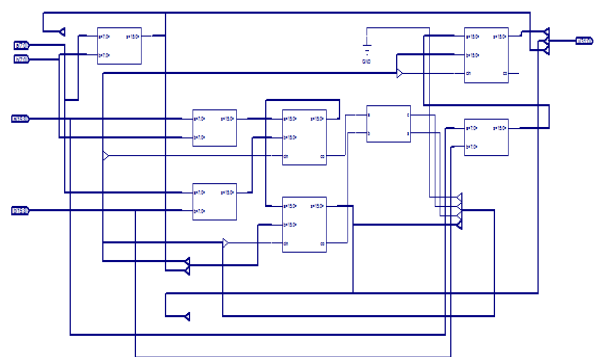

Fig 5. 16X16 RTL Schematic View

\section{SIMULATION RESULTS}

RTL schematic of 16X16 Vedic Multiplier is shown in figure 5. Simulation result waveforms of $4 \mathrm{X} 4$ vedic multiplier, $8 \mathrm{X} 8$ vedic multiplier and 16X16 vedic multiplier are presented in figures 6,7 and 8 respectively. The delay measured is reported in Table 1. 


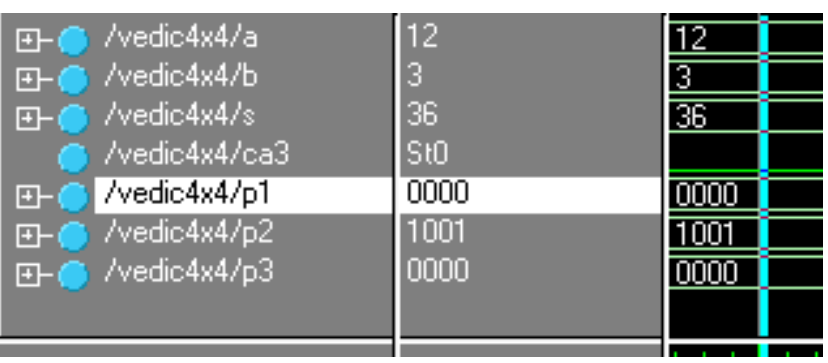

Fig 6. Simulated Result of 4X4 Vedic Multiplier

\begin{tabular}{|c|c|c|}
\hline t-O/vedic8x8/a & 241 & 42 \\
\hline t-1 /vedic $8 \times 8 / \mathrm{b}$ & 10 & $\overline{117}$ \\
\hline 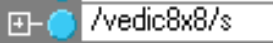 & 2410 & 49114 \\
\hline $0 /$ vedic8x8/ca3 & St0 & \\
\hline t-O/vedic8x8/p1 & 00000000 & 01000110 \\
\hline Ð0/vedic8*8/p2 & 10010110 & 00001010 \\
\hline t四/vedic $8 \times 8 / \mathrm{p} 3$ & 00000000 & 00001110 \\
\hline
\end{tabular}

Fig 7. Simulated Result of 8 X8 Vedic Multiplier

\begin{tabular}{|c|c|c|}
\hline 바 / / vedic16x16/a & 5457 & 1962 \\
\hline t-O/vedic16:16/b & 518 & 6101 \\
\hline 바 / /vedic16x16/y & 2826726 & 11970162 \\
\hline $0 /$ vedic16x16/c1 & St0 & \\
\hline /vedic16:16/c2 & St0 & \\
\hline /vedic16x16/c3 & & \\
\hline Ð-O/vedic16x16/p1 & 0000000111100110 & 1000110101 \\
\hline
\end{tabular}

Fig 8. Simulated result of 16X16 Vedic Multiplier

\section{RESULTS AND DISCUSSION}

As is evident from Table 1, the combinational path delay of the proposed Vedic Multiplier is reduced by approximately $15 \%$. Less delay is equivalent to prompt and quick response of the processor. Results are compared with conventional booth multiplier implemented in [5]. Arithmetic operations through a Vedic multiplier could be performed in less time as compared to a conventional booth multiplier.

TABLE 1.Delay comparison of Conventional and Proposed Vedic Multiplier

\begin{tabular}{|l|l|l|}
\hline $\begin{array}{l}\text { Multiplier } \\
\text { No. of bits) }\end{array}$ & $\begin{array}{c}\text { Conventio } \\
\text { nal Booth } \\
\text { Multiplier } \\
{[5]}\end{array}$ & $\begin{array}{l}\text { Proposed } \\
\text { Vedic } \\
\text { Multiplier }\end{array}$ \\
\hline $4 \times 4$ & $17.86 \mathrm{~ns}$ & $16.437 \mathrm{~ns}$ \\
\hline $8 \times 8$ & $39.28 \mathrm{~ns}$ & $32.395 \mathrm{~ns}$ \\
\hline $16 \times 16$ & $75.23 \mathrm{~ns}$ & $58.909 \mathrm{~ns}$ \\
\hline
\end{tabular}

\section{CONCLUSION}

This paper implements a delay efficient Vedic multiplier for DSP applications. The architecture could be directly implemented in a DSP block requiring multiplier for further calculations. Vedic multiplier could be further implemented for 32 bits and 64 bits which finds application in processor design as well.

\section{REFERENCES}

1. Swami BharatikrishnaTirthaji Maharaja, "Vedic Mathematics', MotilalBanarasidass Publishers, 1965.
2. Y Rana Lakshmanna, GVS Rao,” A Survey on Different Multiplier Techniques"; SSRG International Journal of Electronics ad Communication Engineering( SSRG- IJECE)- Volume 3, March 3, 2016.

3. Rakshith T R and RakshithSaligram, "Design of High speed Low power Multiplier using Reversible logic: a vVedic Mathematical Approach", International conference on Circuits, Power and Computing Technologies (ICCPCT-2013), ISBN: 978-1-4763-4922- 2/13,PP 775-781.

4. VaijyanathKunchigi, Subhash Kulkarni," Simulation of Vedic Multipliers in DCT Applications." International Journal of Computer Applications (0975-8887) Volume 63-No. 16, February 2013.

5. Palladurai K. and K. Hariharan, "Implementation of Signed Vedic Multiplier Targeted at FPGA architectures", ARPN Journal of Engineering and Applied Science, Vol. 10, No. 5, March 2015.

\section{AUTHORS PROFILE}

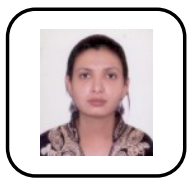

Ms. Nidhi Gaur is currently working as Assistan Professor in Department of Electronics and Communication Engineering, ASET at Amity University, Uttar Pradesh. She has done her M.Tech in VLSI Design from Banasthali University Rajasthan. Her area of research is Front end VLSI design, communication and networking. Currently she is pursuing $\mathrm{PhD}$ from Amity University, uttar Pradesh. She has more than 25 publications in International journals and conferences.

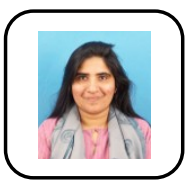

Dr. Anu Mehra received her Masters in engineering from K.U.Leuven, Belgium in the year 1998. She received $\mathrm{Ph} . \mathrm{D}$ in "High Energy physics" from Jamia Millia Islamia, Delhi, India in 2004. After the completion of PhD she went for a post Doc to IMEC, Belgium. She also did a complementary Masters in Engineering there. She joined Amity University, Noida, India in the year 2004. Currently she is working as Professor in Amity School of Engineering and Technology in the Department of Electronics and Communications Engineering.

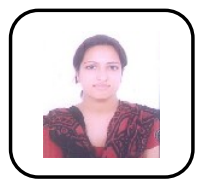

Shikha Bathla, born in Haryana in India, on March 06, 1985. After completing, Bachelor of Technology in the field of Electronics and Communication Engineering from Kurukshetra University, Kurukshetra in 2006. She did her Masters in Technology in the field of Electronics and Communication Engineering with specialization in "VLSI Design" from Banasthali Vidyapith, Rajasthan in 2009. Presently, she is working as an Assistant Professor in the Department of Electronics and Communication Engineering at Amity University, Noida. Her fields of interest lie in VLSI Design and Embedded Systems. She has more than 10 publications in International journals and conferences.

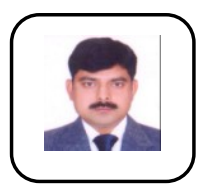

Dr Pradeep Kumar is currently working as an Associate Professor in the Department of Electronics and Communication Engineering, Amity University Uttar Pradesh, Noida, India. He has received his Ph. D. degree from Garhwal University Srinagar (Garhwal) Uttaranchal, India, in 2006. Dr Kumar's has 14 years of teaching and research experience, most recently focusing on VLSI, microelectronics, device modelling and simulation, design and verification using Verilog and systemverilog. He has published more than fifty research papers in national and international Journals/conferences. 